\title{
The Control of Tropical Diseases Is the Health Goal to Achieve
}

\author{
Gilberto Antonio Bastidas Pacheco 1, *, Daniel Alejandro Bastidas Delgado², \\ Geraldine Eleanni Bastidas Delgado ${ }^{2}$ \\ ${ }^{1}$ Department of Public Health, Faculty of Health Sciences, University of Carabobo, Valencia, Venezuela \\ ${ }^{2}$ School of Medicine, Faculty of Health Sciences, University of Carabobo, Valencia, Venezuela \\ Email address: \\ bastidasprotozoo@hotmail.com(G. A. B. Pacheco), Daniel_mdc_uc@hotmail.com(D. A. B. Delgado), \\ geralbastidas4@gmail.com (G. E. B. Delgado) \\ ${ }^{*}$ Corresponding author
}

\section{To cite this article:}

Gilberto Antonio Bastidas Pacheco, Daniel Alejandro Bastidas Delgado, Geraldine Eleanni Bastidas Delgado. The Control of Tropical Diseases Is the Health Goal to Achieve. Science Journal of Public Health. Special Issue: Tropical Diseases Impact on Public Health. Vol. 7, No. 5, 2019, pp. 163-166. doi: 10.11648/j.sjph.20190705.15

Received: September 9, 2019; Accepted: September 29, 2019; Published: October 10, 2019

\begin{abstract}
In the world, one billion people are affected by tropical diseases, mainly people with low economic resources in rural and marginal urban regions. Being an important public health problem, prevention and control have been attempted. Achieving relevant progress in this regard. The objective is to show aspects related to the sanitary approach of tropical diseases. Based on the documentary review of virtual databases based on systematic analysis. The findings were grouped into: advances in the control of tropical diseases; tropical diseases from the prism of human rights; and challenges to consider for the maintenance of the control and extension of the prevention of tropical diseases. It is concluded that despite the complexity of the transmission of tropical diseases, great advances have been made in the control and prevention of some of them; that the principles of participation, non-discrimination and responsibility guarantee the human right to health in tropical diseases; that the progress achieved in the control and prevention of tropical diseases requires international support, consideration of environmental factors, timely health response, professional training, community participation and the promotion of research on the subject.
\end{abstract}

Keywords: Tropical Diseases, Public Health, Risk, Prevention

\section{Introduction}

Infectious diseases of hot and humid climates that occur only or mainly in tropical regions, from which it derives its name, and among which malaria, leishmaniasis, schistosomiosis, onchocerciasis, lymphatic filariosis, Chagas disease, African trypanosomiasis and dengue, because of their enormous impact on collective health, must be continually addressed to control them and why not eradicate them [1], as it is known, that in the world one billion people are affected by some of these Pathologies mainly people of low economic resources of marginal rural and urban regions [2].

For example, in America, 25 million people are at risk of acquiring schistosomiosis, 70 million individuals are at risk of infection by Chagas disease, in malaria 120 million people can get sick, in visceral leishmaniasis there is a risk in 72 million and in cutaneous in 240 million $[3,4]$, this despite the fact that tropical diseases are not of recent origin or approach, but still represent a serious public health problem, because they are neglected in many cases with severe economic consequences for countries and very especially for affected families, because these diseases can become chronic, disabling and deadly.

The risk of suffering some kind of tropical disease because they are not sufficiently attended by the health agencies of the countries becomes enormous, although two of the groups in which these diseases were distributed according to the control and elimination measures make the reduction viable or disappearance of the risk for several of them, mainly those that were included in the groups: diseases that can be 
controlled or drastically reduced and diseases that can be eliminated $[2,5]$.

In this sense, structures aimed at the surveillance, prevention and control of such diseases as the unit of neglected, tropical and vector-borne diseases, whose main mission is to strengthen information management, arise within the Pan American Health Organization of human talent and materials in the prevention, control and elimination of tropical, infectious, and emerging or reemerging diseases based on operational research for the development of technically feasible, economically viable and socially accepted health programs. This is due to the great importance that strategies and lines of action have for the control of tropical diseases for the achievement of cooperation between different social sectors and for resource mobilization, as well as for the formation of human talent and development of infrastructure $[3,6]$.

It is also key for the prevention, control and elimination of tropical diseases that health plans and policies are built on the basis of international standards in the formulation, implementation and evaluation, but with their respective operational technical adjustments in local programs due to the social and cultural differences that the different countries have, and even the population groups within the same country. Given the importance that tropical diseases have for public health is that aspects related to their sanitary approach are shown, as a fundamental objective of the following document.

\section{Methodology}

The present work was based on the documentary review of scientific literature in electronic format on some aspects related to the approach of tropical diseases based on systematic analysis, for this, virtual bases were used based on descriptors or keywords related to constructs or proposals. The documents resulting from the search after analyzing the relevant ideas were grouped into 3 aspects that can be read independently, in order to facilitate its review: advances in the control of tropical diseases; tropical diseases from the prism of human rights; and challenges to consider for the maintenance of the control and extension of the prevention of tropical diseases.

\section{Results}

\subsection{Advances in the Control of Tropical Diseases}

There are many achievements in the control of tropical diseases with the application of the five interventions recommended by the World Health Organization to defeat tropical diseases, namely: chemoprophylaxis, innovative and intensified care of these diseases, ecology and vector management, public and veterinary health service and supply of safe water, sanitation and hygiene $[1,7]$.

In relation to the administration of medications to the community at risk to reduce morbidity and prevent transmission, in what is known as chemoprophylaxis (the first of the five interventions recommended by the WHO), treatment has been provided against at least 100 million of people at risk of contracting any of these diseases, that is, to $62.9 \%$ of those who need them, in this sense the therapeutic coverage has been increased to $59.3 \%$, for example, for lymphatic filariosis the highest achieved by any program of massive administration of drugs, the progress is such that the number of countries that have eliminated lymphatic filariosis as a collective health problem is increasing [1].

In the field of innovative and intensified care that includes the sum of the different existing interventions against some tropical disease, almost all complex, from drugs to surgeries immersed in health programs, despite the limitations in the widespread use of existing intervention tools. These comprehensive control actions have allowed significant reductions in the number of new cases of American trypanosomiosis and visceral leishmaniasis in Bangladesh, India and Nepal. In addition, universal screening of Chagas disease has been achieved in blood donors in Latin America $[1,8]$.

Vector control is an indispensable strategy for reducing the risk of transmission of some of the tropical diseases based on the judicious use of insecticides and vector interception measures. The attention of tropical diseases of zoonotic origin in the field of veterinary health has been equally important in reducing the risk of acquiring tropical diseases, especially because rural and even marginal urban populations live in close contact with their domestic animals, as well as for agricultural, transport and human consumption [1,9].

Finally, the supply of healthy water and sanitation and hygiene are critical factors, recognized for their multisectoral nature, in the treatment of tropical diseases, specifically in the prevention and care of these diseases, because many of the pathogens responsible for tropical diseases they proliferate in areas where the water supply and sanitation is poor and of course where knowledge about the biology of tropical diseases is poor $[1,10]$.

\subsection{Tropical Diseases from the Prism of Human Rights}

The approach and analysis of tropical diseases from the perspective of human rights, with particular interest in developing countries, is a matter of concern for the United Nations, as they are rights applicable to all human beings, under the dynamics of the obligation that government health authorities have on the health side towards society and, on the other hand, the right of society to demand guarantees as regards health, both in terms of health care timely health as to the determinants of it [11].

In this sense, tropical diseases, specifically their control, require immediate and appropriate measures to the environmental transmission conditions based on participation, non-discrimination and responsibility as human rights principles, in order to guarantee them people at risk of contracting any tropical disease the availability, accessibility and good quality of health prevention and control programs, detached from all discrimination, based on the population 
and in the resolution of specific local needs, of course as part of the official systems health to avoid undermining them [11]

The control of tropical diseases involves the participation of the affected communities in the implementation of the programs, prior to their involvement in setting their priorities, it is an active, free and profitable participation, which does not neglect surveillance, as From this, the corrective measures to which the implemented health programs take place can take place. The progress achieved in the control of tropical diseases, and those that are still to be achieved, require the strict application of non-discrimination in the application of health programs, for this it is essential to identify vulnerable groups (in many cases women [they suffer from greater social stigma] and children with low economic resources), so that they are immediately subject to health intervention [11-13].

Governments should be responsible for the sanitary measures for the control of tropical diseases that they implement, in terms of obligations, rights, transparency in procedures and measures, as well as in the mechanisms of damage repair. The human rights approach as a key tool to attack tropical diseases is also supported by the World Health Organization, as it promotes the inclusion of tropical disease control in health programs, earmarking specific budget items for programs that in this sense they develop and in their constant struggle to eliminate stigma and discriminatory attitudes associated with diseases $[11,14,15]$.

\subsection{Challenges to Consider for the Maintenance of Control and Extension of the Prevention of Tropical Diseases}

Tropical diseases strongly related to poverty, because there are endemic, many of them ancient that have plagued humanity for centuries, can nevertheless be subject to prevention and sanitary control, even those that go unnoticed or ignored, because the Affected people lack political representation, voice, to speak for them. It is here that poverty-related diseases are of great incentive to global health organizations in the area of control, because prevention and treatment needs are great. Therefore, it is proposed, this is done by global health entities [1-3]:

1. Prioritize epidemiological surveillance in order to determine the obstacles that prevent the execution of control measures and establish corrective measures in relation to the capacity of the national health system of each country.

2. Because population groups may be simultaneously vulnerable to several tropical diseases, innovative methods must be used to address several of these at the same time to accelerate the reduction of prevalence and move towards elimination.

3. It is important to create innovative and simultaneous methods of care for tropical diseases, the promotion of operational research, that is, the scientific study of all the variables involved in the genesis and maintenance of the transmission of these diseases.

4. Establish follow-up groups made up of representatives of the community, that is, those affected and representatives of the health authorities. This measure strengthens community participation, essential for the success of any intervention.

5. Promote the constant training of health personnel in the field of tropical diseases, the only way to ensure effective, safe and good quality health interventions.

6. Promote health control programs for tropical diseases in hard-to-reach areas such as forests, as well as border areas, often neglected.

7. Achieve the supply, in the prevention of tropical diseases, of large-scale medicines of high quality, proven efficacy, safe, single dose, at regular intervals and with optimal coverage. This is based on the improvement of the affordability of preventive chemotherapy.

8. Support large-scale health interventions on existing health platforms, thereby optimizing installed capacity, this because the integration of intervention activities allows for greater cost-benefit, because logistics is easier and better synchronization.

9. Strengthen local and regional decision-making, without these contemplating major alterations to national health programs in the field of tropical diseases, but which does promote the optimal and integrated use of resources against one or several tropical diseases.

10. Promote the work, collaboration and inter-disciplinary and interdisciplinary participation of different sectors of knowledge to face the scourge of tropical diseases.

\section{Conclusion}

All the interventions recommended by the WHO in the fight against tropical diseases stand out in reducing the risk of transmission of the same as long as the necessary resources and attention are allocated to them. The efforts of countries should be maintained to ensure the efficient application of control interventions, with special interest in monitoring and surveillance, in the search for alternative drugs and to ensure efficient notification for the maintenance of optimal levels of coverage, based on health education, of course, adjusted to the local environment of the population subject to health action.

It is committed to the global integration of tropical disease control plans and policies based on the strengthening of intersectoral collaboration and unreserved expansion of instruments with integration of approach approaches, the latter of a multidimensional nature in consideration of the human binomial -animal. With these measures, poverty is combated, since programs to combat tropical diseases contribute to the reduction of the economic burden experienced by affected individuals and their families, as well as reduce or limit disability, thereby recovering or increases people's capacity to generate income and contribute to the economic growth of their country.

The success of health programs for the prevention and control of tropical diseases requires strict compliance with human rights under the principles of effective participation, 
non-discrimination and community and government responsibility, as an exclusive maneuver to improve the quality of life of populations that are at risk of contracting any of these diseases, it is then about limiting discrimination; increase effective participation in the identification of local health priorities, in the design, implementation and monitoring of the health program; and in achieving the responsibility that governments have in terms of health system administrator, as well as in the right that assists the population to demand it.

There are at least ten challenges that health authorities and the population itself vulnerable to tropical diseases must consider in order to maintain the control achieved so far and be able to extend the prevention of these diseases to other populations at risk. The challenges are summarized as follows: epidemiological surveillance, simultaneous approach to several tropical diseases, operational research, community participation, staff training, care of border populations and jungle regions, preventive chemotherapy, large-scale health interventions, strengthening local decisionmaking and regional, and intersectoral and inter disciplinary work.

\section{Competing Interests}

The authors declare no competing interests.

\section{Authors' Contributions}

All authors were equally participated in this paper.

\section{References}

[1] WHO. The integration of neglected tropical diseases into global health and development. Fourth WHO report on neglected tropical diseases. Synopsis. Geneva, World Health Organization, 2017 (WHO/HTM/NTD/2017.02). License: CC BY-NC-SA 3.0 IGO. [Cited July 12, 2019]. Available in: http://apps.who.int/iris

[2] PAHO. Neglected infectious diseases: Classification of DIA according to control and elimination measures; 2016. [Cited May 15, 2019]. Available in: https://www.paho.org/hq/dmdocuments/2017/neglectedinfectious-diseases-2017-info-jointed-spa.jpg

[3] PAHO. Neglected, Tropical and Vector-borne Diseases. 2016. [Cited January 28, 2019]. Available in: https://www.paho.org/hq/index.php?option=com_content\&vie $\mathrm{w}=$ article\&id=5398:neglected-tropical-vector-bornediseases\&Itemid=1074\&lang=es. s/f

[4] Arria M, Rodríguez-Morales A, and Franco-Paredes C.
Ecoepidemiology of Tropical Diseases in countries of the Amazon Basin. Peruvian Journal of Experimental Medicine and Public Health 2005; 22 (3): 236-240. Available in: http://www.scielo.org.pe/scielo.php?script=sci_arttext\&pid=S 1726.

[5] Hotez P, Bottazzi M, Franco-Paredes C, Ault S, and Periago M The neglected tropical diseases of Latin America and the Caribbean: a review of disease burden and distribution and a roadmap for control and elimination. PLoS Neglected Tropical Diseases 2008; 2 (9): e300. doi: 10.1371/journal.pntd.0000300.

[6] Akinsolu F, de Paiva V, Souza S, and Varga O. Patent landscape of neglected tropical diseases: an analysis of worldwide patent families. Global Health 2017; 13 (1): 82. doi: 10.1186/s12992-017-0306-9.

[7] Reeder J, Kieny M, Peeling R, and Bonnici F. What if communities held the solutions for universal health coverage? Infectious Diseases of Poverty 2019; 8 (1): 74. doi: 10.1186/s40249-019-0586-9.

[8] Souto D, Volpe J, Gonçalves C, Ramos C, and Kubota L. A brief review on the strategy of developing SPR-based biosensors for application to the diagnosis of neglected tropical diseases. Talanta; 205: 120122. doi: 10.1016/j.talanta.2019.120122.

[9] Dean L, Tolhurst R, Nallo G, Kollie K, Bettee A, and Theobald S. Neglected Tropical Disease as a 'Biographical Disruption': Listening to the Narratives of Affected Persons to Develop Integrated People Centred Care in Liberia. PLoS Neglected Tropical Diseases 2019; 13 (9): e0007710. doi: 10.1371/journal.pntd.0007710.

[10] Amolegbe S, Akinremi C, Adewuyi S, Lawal A, Bamigboye $\mathrm{M}$, and Obaleye J. Some nontoxic metal-based drugs for selected prevalent tropical pathogenic diseases. Journal of Biological Inorganic Chemistry 2017; 22 (1): 1-18. doi: 10.1007/s00775-016-1421-4.

[11] WHO. Tropical diseases. [Cited February 28, 2019]. Available in: https://www.who.int/topics/tropical_diseases/es/

[12] Ton T, Mackenzie C, and Molyneux H. The burden of mental health in lymphatic filariasis. Infectious Diseases of Poverty 2015; 4: 34. doi: 10.1186/s40249-015-0068-7.

[13] Hofstraat K, and van Brakel W. Social stigma towards neglected tropical diseases: a systematic review. International Health 2016; 8 Suppl 1: i53-70. doi: 10.1093/inthealth/ihv071.

[14] Barogui Y, Diez G, Anagonou E, Johnson R, Gomido IC, Amoukpo H, Bachirou Z, Houezo J, Saizonou R, Sopoh E, and Asiedu K. Integrated approach in the control and management of skin neglected tropical diseases in Lalo, Benin. PLoS neglected Tropical Diseases 2018; 12 (6): e0006584. doi: 10.1371/journal.pntd.0006584.

[15] Malecela M. Reflections on the decade of the neglected tropical diseases. International health 2019; 11 (5): 338-340. doi: 10.1093/inthealth/ihz048. 